\title{
Challenges to Establish Effective Public-Private Partnerships to Address Malnutrition in All Its Forms
}

\author{
Jessica Fanzo $^{1,2,3 *}{ }^{\circledR}$, Yusra Ribhi Shawar ${ }^{2,1}{ }^{\circledR}$, Tara Shyam $^{4}$, Shreya Das ${ }^{5}$, Jeremy Shiffman ${ }^{2,1} \unrhd$
}

\begin{abstract}
Background: Every country is affected by some form of malnutrition. Some governments and nutrition experts look to public-private partnerships (PPPs) to address the burden of malnutrition. However, nutrition-related PPPs face opposition, are difficult to form, and there is limited evidence of their effectiveness.

Methods: We conducted a literature review and 30 semi-structured interviews with individuals involved in or researching nutrition-related PPPs to identify the factors that shape their creation and effectiveness in food systems.

Results: Several factors make it difficult to establish nutrition-related PPPs in food systems: a lack of understanding of the causal pathways behind many nutrition problems; a weak architecture for the global governance of nutrition; power imbalances between public and private sector nutrition actors; and disagreements in the nutrition community on the advisability of engaging the private sector. These complexities in turn make it difficult for PPPs to be effective once established due to goal ambiguity and misalignment, resource imbalances, and weak accountability.

Conclusion: If effective nutrition-related PPPs are to be established, private sector conflicts of interest must be addressed, trust deficits between private and public sector actors must be surmounted, and evidence must be assessed as to whether PPPs can achieve more for public health nutrition than private and public sector actors working separately.

Keywords: Public-Private Partnerships, Food Systems, Nutrition, Accountability, Trust, Transparency

Copyright: @ 2021 The Author(s); Published by Kerman University of Medical Sciences. This is an open-access article distributed under the terms of the Creative Commons Attribution License (https://creativecommons.org/licenses/ by/4.0), which permits unrestricted use, distribution, and reproduction in any medium, provided the original work is properly cited.

Citation: Fanzo J, Shawar YR, Shyam T, Das S, Shiffman J. Challenges to establish effective public-private partnerships to address malnutrition in all its forms. Int J Health Policy Manag. 2021;10(12):934-945. doi:10.34172/ijhpm.2020.262
\end{abstract}

Article History:

Received: 27 May 2020 Accepted: 19 December 2020 ePublished: 16 January 2021

View Video Summary

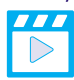

*Correspondence to:
Jessica Fanzo

Email: jfanzo1@jhu.edu

\section{Key Messages}

Implications for policy makers

- Policy-makers should decide if a partnership with private sector is warranted and if so, that there is sufficient causal pathways to impact, strong governance mechanisms, and no conflicts of interest between actors of the partnership.

- If policy-makers are to partner with private sector, the architecture of the engagement needs to be transparent, open, and inclusive with a main goal to improve public health nutrition.

- Putting in place robust accountability mechanisms within established public-private partnerships (PPPs) will be critical for governments so that they can steward, monitor and incentivize private sector actors to work towards promoting healthy diets and nutrition within food systems.

Implications for the public

If governments are to engage with private sector food system actors, they need to exert their power and ensure that they are protecting citizens and promoting public health through those engagements. They cannot be passive bystanders. Our research found that nutrition-related publicprivate partnerships (PPPs) in food systems often fail because of a lack of governance, power imbalances and mistrust. Because of these challenges, consumers are often weary of food and beverage industry's motives towards improvements in public health. Outside of PPPs, consumers look to governments to keep these industry players in check by developing evidence-based food-based dietary guidelines, supporting fiscal instruments such as taxes on soda and unhealthy junk food, and regulating advertising junk food to children. We hope this research will eventually change policies so that PPPs can be more effective in ensuring that food systems work for citizens by prioritizing public health nutrition before any other motives.

\section{Introduction}

Every country is affected by malnutrition in some form, be it undernutrition, micronutrient deficiencies, or overweight and obesity, with some countries struggling with multiple forms. ${ }^{1,2}$ One of the most impactful solutions to address this challenge is to improve the nutrient-density of diets and dietary patterns for populations to reduce all forms of malnutrition..$^{3-7}$ To do this, actions need to be taken through interconnected food systems. But diets are changing along with dynamic development, urbanization, and shifting demographics. ${ }^{8}$ Sub-optimal diets are now one of the top risk factors globally for deaths and disability-adjusted life-years 
lost due to non-communicable diseases (NCDs), surpassing tobacco smoking and high blood pressure. ${ }^{9}$ To realign food systems and to respond to dietary transitions, it is important to establish accountability mechanisms and incentives that aim to improve the affordability and accessibility of foods and beverages that support healthy diets and address all forms of malnutrition. ${ }^{10-14}$

Both the private and public sectors play significant roles in shaping diets through the food supply and food environments. ${ }^{15,16}$ The majority of food consumed by the world's population involves a "broad range of commercial enterprises"-from large, multi-nationals to small- and medium-scale enterprises (SMEs) involved in food transformation including agribusiness, food product processing, reformulation and packaging, meal manufacturers, and the advertising and marketing industry. ${ }^{17}$ These enterprises are made up of a diverse set of actors including food and beverage manufacturers, retailers, food service providers, industry trade associations, wholesalers, distributors, importers and exporters. ${ }^{15}$ They range from informal, less structured small enterprises to well-organized, large-scale trans-national companies. There are also actors that are not necessarily directly involved in the food system and its activities but their products and services influence food system change, such as the mobile phone industry and communications agencies.

The private sector also has significant power across food systems, with involvement in almost all aspects of the production, processing, distribution, marketing and sale of food that consumers eat every day. ${ }^{18-20}$ The private sector has the capacity for market penetration far beyond that of the public health sector. ${ }^{21}$ Whilst the private sector has made innovations to promote healthy lifestyles ${ }^{22}$ or improve the nutrition of their portfolio of products (ie, fortification), a significant proportion of food products do not contribute to healthy lifestyles and diets in general, and many food and beverage companies do not fully align with consumer health..$^{23,24}$

Many of the actors working in and governing food systems are calling for the private sector, in all its shapes, forms and sizes, along with its supporting ecosystem, to become increasingly aligned with public nutrition and health policy. Some look to public-private partnerships (PPPs) as a potential vehicle for realizing public health goals - in this case public health nutrition-while stimulating private investment and additional resources to foster the development of food systems that provide healthier foods. ${ }^{25-30}$ PPPs are alliances designed to achieve common goals benefiting societies and all partners ${ }^{31-33}$ but can entail a mixture of interactions involving a range of different activities, processes and structures. ${ }^{34}$

There is a range of partnerships in nutrition depending on the end goal. They can be research driven, commercially focused, or designed to promote public health initiatives. Some partnerships involve a minimal level of commitment from each partner, whereas in other situations the partnership involves greater commitment with pooled resources, shared decision-making and obligations. ${ }^{35}$ Between these two extremes lie a wide range of levels of commitment between partners. ${ }^{33}$ There are also public private engagements which is a broader area capturing all modalities of engagement between the public and private sectors from informal collaborations to more formalized partnerships. ${ }^{36}$

The World Health Organization (WHO) defines PPPs as "a collaboration between public-and private-sector actors within diverse arrangements that vary according to participants, legal status, governance, management, policy setting, contributions and operational roles to achieve specific outcomes." ${ }^{37}$ In the field of nutrition, there is no single definition of a PPP, no consensus on how they should be defined and inadequate documentary evidence of the efficacy of such partnerships. ${ }^{34,38-40}$

Ideally, PPPs should be designed first and foremost to benefit public health goals, in this case, public health nutrition, while stimulating private investment and additional resources to foster development. Discussion around the effectiveness of PPPs is polarized within the food systems community, and in particular, in the field of nutrition. . $^{1633,41-42}$ On the one hand, some argue that PPPs offer the potential to improve diet and nutrition outcomes by harnessing resources, reach, relationships and knowledge from both government and private sector actors. ${ }^{1,42}$ Others have reservations about engaging with food and beverage industries, deeming them as major contributors to the malnutrition burden. ${ }^{1,43-46}$ "The question, then, is what is the best way to work with industry actors, whose products contribute to chronic diseases, and whose practices undermine policy responses to NCDs, without jeopardizing public welfare." ${ }^{46}$

In this paper, we investigated the challenges of establishing PPPs in food systems that are focused on improving diets and nutrition, and why they struggle to succeed. We identified the factors shaping the formation and development of PPPs, highlighting challenges to their emergence as well as obstacles that facilitate their growth and effectiveness in contributing to public health and nutrition policy. This paper focuses only on PPPs that take place in food systems with an aim to improve diets and nutrition. Although there are many other types of PPPs that are geared towards improving nutrition, and many other types of PPPs within food systems that shape other outcomes (eg, economic growth, agriculture productivity and environmental sustainability), taking a broader approach is beyond the remit of this paper.

\section{Methods \\ Data Collection}

We collected information on PPPs by searching Google Scholar and PubMed since 2000. Eighteen search terms and their combinations were used and are shown in Table 1 . We restricted the literature review to articles in English that were broadly associated with PPPs or private sector involvement in the nutrition field. We excluded articles that did not discuss PPP emergence and/or effectiveness in the nutrition field. The search resulted in 113 peer review and grey literature articles which were then divided into the following categories: critiques, reviews or analyses of nutrition-focused PPPs; private sector involvement in nutrition research; case studies of nutrition-focused PPPs; and other PPPs with a focus on 
public health or agriculture.

We also conducted 30 semi-structured interviews by phone or Skype, between August 2018 and February 2019, with those who had researched PPPs, those directly involved with PPPs, and those with extensive knowledge of private or public sector involvement in nutrition. Using a purposive rather than sampling selection strategy, we selected individuals through the literature review and by asking those interviewed whom they considered to be most centrally involved in nutrition-focused PPPs, in academia and the public and private sectors. Key informants were from high-, middle- and low-income countries, representing various organizational affiliations with expertise in food systems and nutrition as shown in Table 2. One limitation of this sampling strategy is that it may be prone to selection bias. However, three of the authors of this study are outsiders to the nutrition field, and a purposeful effort was made to include a balanced reflection of perspectives from those engaged in both private and public sectors, as well as those involved in various subjects in the nutrition field. Given the lack of representation from those that come to nutrition from a position of engagement with undernutrition and micronutrient deficiencies as well as those from low- and middle-income settings, it would be valuable for future studies concerned with PPPs in nutrition to interview these actors as a means of further interrogating our findings. We continued interviewing until we reached theoretical saturation ${ }^{47}$ - the point at which all major themes have been identified and additional interviews are unlikely to reveal new information.

The interviews lasted approximately one hour on average and were recorded and transcribed with permission from the key informants. We obtained informed consent from all research participants. All interview transcripts and notes were de-identified and secured in password-protected documents to ensure respondent confidentiality. Drawing on the findings from the literature review, questions were focused on successes and challenges of establishing high quality and impactful PPPs. We tailored questions to each interviewee's expertise.

\section{Data Analysis}

To analyze factors shaping PPP establishment and effectiveness, we conducted a thematic analysis in Microsoft Word, drawing

Table 1. Search Terms for Literature Review

\begin{tabular}{ll}
\hline Combined Searches With “Nutrition” & Combined Searches With “PPPs" \\
\hline Public-private partnerships & Diets \\
\hline Industry & Food systems \\
\hline Business & Food sector \\
\hline Impact assessment PPPs & Nutrition \\
\hline Collaborative governance & Healthy food \\
\hline Commercial sector & Obesity \\
\hline \multirow{3}{*}{ Market-based approach } & Undernutrition \\
\cline { 2 - 2 } & Malnutrition \\
\cline { 2 - 2 } & Nutrition AND health outcomes \\
\cline { 2 - 2 }
\end{tabular}

Abbreviation: PPPs, public-private partnerships. on information from key informant interviews and collected literature. Grounded in governance, policy and PPP-specific scholarship, ${ }^{48,49}$ we initially coded the collected data under the broad categories of challenges and opportunities/ strengths with sub-codes: issue characteristics (the nature of the issue), policy environment (the external policy and market context that PPPs operate in), PPP governance and management (the internal structure and operation of the PPP), and the actors involved (the nature and dynamics of the involved actors). These sub-codes were highlighted as being key general factors in determining network, organizational, and/or PPP establishment and effectiveness in the conceptual and theoretical scholarship. The sub-codes evolved as more empirical data - from the key informant interviews and literature - was collected. For example, causal ambiguity became a key sub-code under issue characteristics;

Table 2. Interviewee Affiliations

\begin{tabular}{|c|c|}
\hline Organization Type & Affiliation \\
\hline \multirow{9}{*}{ Academic/Research } & City University of New York \\
\hline & Cornell University \\
\hline & Institute of Medicine \\
\hline & International Food Policy Research Institute \\
\hline & New York University \\
\hline & Pennsylvania State University \\
\hline & SR ${ }^{a}$ Strategy \\
\hline & University of Guelph \\
\hline & Virginia Tech \\
\hline \multirow{8}{*}{ Private sector } & BASF \\
\hline & Compass Group Canada \\
\hline & Emerging Ag Inc. \\
\hline & Partnering with Purpose \\
\hline & PepsiCo \\
\hline & Royal DSM \\
\hline & Unilever \\
\hline & WBCSD \\
\hline \multirow{7}{*}{$\begin{array}{l}\text { Public sector (including } \\
\text { nonprofits) }\end{array}$} & 1000 Days \\
\hline & BRAC \\
\hline & IDRC \\
\hline & IFIC Foundation \\
\hline & MicroNutrient Initiative \\
\hline & PATH \\
\hline & Save the Children USA \\
\hline \multirow{4}{*}{$\begin{array}{l}\text { Combined private and } \\
\text { public sector alliance }\end{array}$} & MotherFood International \\
\hline & Sight and Life \\
\hline & GAIN \\
\hline & SUN Business Network \\
\hline \multirow{2}{*}{$\begin{array}{l}\text { Intergovernmental } \\
\text { organizations }\end{array}$} & UNICEF \\
\hline & WHO \\
\hline
\end{tabular}

Abbreviations: BASF, Badische Anilin und Soda Fabrik; Royal DSM, Dutch State Mines; WBCSD, World Business Council for Sustainable Development; BRAC, Bangladesh Rural Advancement Committee (now Building Resources Across Communities); IDRC, International Development Research Centre; IFIC, International Food Information Council; PATH, Program for Appropriate Technology in Health GAIN, Global Alliance for Improved Nutrition; SUN, Scaling Up Nutrition; UNICEF, United Nations Children's Fund; WHO, World Health Organization.

${ }^{a} \mathrm{SR}$ is the name of an interviewee. 
goal alignment, resource acquisition, accountability, and power imbalance became prominent sub-codes under PPP governance and management; and mistrust and fragmentation became key sub-codes under actors involved. To minimize bias and validate the accuracy of the findings, three of the authors coded the data simultaneously and the data sources were triangulated, always corroborating information from interviews with written sources. In reporting the interview data, each key informant was assigned a number.

\section{Results}

A review of evidence from the literature and the interviews revealed four primary factors that make it difficult to establish nutrition-related PPPs. These factors in turn shape the quality and efficacy of nutrition-related PPPs once established: the research reveals that PPPs commonly face challenges in creating alignment and clarity of goals, acquiring and balancing resources and establishing robust accountability mechanisms.

Factors That Pose Challenges to Nutrition PPP Establishment Four sets of factors make it difficult to establish nutritionrelated PPPs. The first concerns the complexity of nutrition's causal pathways. The second relates to the global governance of nutrition. The third pertains to power imbalances between public and private sector actors in nutrition. The fourth concerns mistrust that pervades the nutrition space surrounding engaging the private sector. The prominence of each factor depends on the nutrition issue being addressed.

\section{Nutrition's Complex Causal Pathways}

Nutrition's causal pathways are complex. There are multiple contributing factors to undernutrition in the form of stunting and wasting, micronutrient deficiencies, overweight and obesity, and diet-related NCDs. ${ }^{2}$ Each of these manifestations is biologically multifarious and complex, with a range of contributing factors and outcomes on health and well-being. ${ }^{50-53}$ There are also gaps in knowledge on underlying and immediate undernutrition and obesity causes and determinants, ${ }^{54-56}$ as well as the varying impacts of interventions at different stages of the life cycle. ${ }^{54,55}$ For example, there are still gaps in evidence on how to effectively and sustainably prevent the onset of obesity through foodbased solutions. ${ }^{57-60}$ Furthermore, there is a lack of data with robust metrics on what people consume, the cost of diets and food environments in low- and middle-income contexts. ${ }^{61-63}$ This makes it difficult to establish PPPs, given uncertainties about what to focus on, the role of each actor involved and the implementation of critical nutrition interventions such as shaping consumer behaviors and designing the choice architecture of food environments (I9, I12). ${ }^{64}$ Two interviewees (I9, I12) expressed similar concerns stemming from the literature that a lack of nuanced understanding of the causal pathways, the complexity of these pathways and the potential to do harm without a clear understanding of them, heighten reservations to act and partner. One respondent compared the difficulties of establishing causality and goals in nutrition with climate change:
"In the case of climate change, you can [estimate] the aggregate impact of automobile emissions or coal plant emissions and the goal becomes reducing those emissions. But the ability to demonstrate the impact of that on the temperature of the oceans and halting the receding of glaciers is far down the road, right? So there's an analogy there in nutrition of can we agree on some approximate endpoints or is the only relevant nutrition goal going to be the more ultimate, biological endpoints that we tend to care about?" (I12).

There is no silver bullet to address malnutrition in all its forms given nutrition's multi-temporal, multi-faceted, multisectoral, multi-disciplinary nature. ${ }^{65,66}$ This makes it difficult to measure impact and incentivize actors to come together to work on changing nutrition outcomes-important precursors for establishing a PPP..$^{17,40,67-69}$ Policy-makers and implementers can be left in a void, without guidance to determine whom to partner with and how. ${ }^{70}$ One respondent noted this difficulty:

"Structurally, our field is very multidimensional and complex. This is in contrast to PPPs in public works. The outcomes and what needs to be done is very clear in infrastructure PPPs, but indicators in nutrition [are] not very clear" (I9).

However, tackling micronutrient deficiencies is an area of nutrition that is more tractable and has therefore seen clearer evidence of impact with isolated interventions, such as highdose vitamin A supplementation programs implemented in many countries given to children under the age of five years. ${ }^{71}$ Because it is a supplement, governments, the United Nations (UN) and non-governmental organizations partner with vitamin A capsule manufacturers. Another example is readyto-use therapeutic foods used to treat severe cases of acute malnutrition. Agencies such as the United Nations Children's Fund (UNICEF) must engage the private sector to ensure quality control and consistent productivity of the product. ${ }^{72,73}$ As a result, the availability of literature on this type of intervention suggests PPPs lend themselves to micronutrient fortification, biofortification and supplementation initiatives, although independent evaluations that dissect how those PPPs functioned and what made them successful are few. ${ }^{38}$

There is also insufficient evidence and data that nutritionrelated PPPs have made an impact on improving diets through the food systems lens. ${ }^{34,74-77}$ Most PPPs are still in early or pilot phases that do not allow for proper evaluation, and many exist as pilots with less certainty for scale-up to serve consumers that need interventions or provisions the most. ${ }^{78}$ In our own search, we found many examples of PPPs, but very few were examined by an external third party for their effectiveness or impact. There has been minimal evaluation of what has made PPPs effective and what has hindered their progress $^{79}(\mathrm{I} 1, \mathrm{I} 5, \mathrm{I} 6, \mathrm{I1})$.

Dysfunctional Global Governance of Nutrition and its Actors The second challenge concerns the actors in nutrition and the field's governance structures. Levine and Kuczynski have argued that the nutrition field has a "dysfunctional international architecture," is underfunded and has 
lackluster leadership. ${ }^{65,80,81}$ Observers describe the field as a loose collection of entities without unified vision. ${ }^{65,80,81}$ This paper was written over ten years ago however, and the field of nutrition has changed. Following the publication of that paper, the Scaling Up Nutrition movement was formed, and several Lancet series and Commissions on undernutrition, obesity and food systems have been published since, creating more understanding and evidence of what needs to be done to improve nutrition outcomes.

Yet still, individuals working in specialized areas such as humanitarian relief, obesity and micronutrient deficiencies are often isolated from one another and other sectors. This fragmentation fuels duplication of efforts and competition for resources, rather than collaboration and partnership. Many of these communities, made up of numerous diverse players, have developed their own distinct ideologies or different world views, including on how to engage with private sector. This division also puts excessive pressure on governments to determine where and how they should act, and with whom they should align.

"I see an inability to come together on a coherent set of demands within the nutrition community as a function of some people having stronger ideological opposition to the industry and PPPs than others" (I12).

The issue of trust between some actors in the nutrition community and the private sector plays out in multiple and diverse ways when addressing malnutrition, some of that due to the different approaches taken when dealing with one type of burden. ${ }^{82}$ First, in the undernutrition space overall, programmatic and funding allocation decisions are framed as a stark choice between a preventative approach (also called a nutrition-sensitive approach), which addresses the underlying causes of malnutrition, and a treatment approach (also called a nutrition-specific approach), which addresses the immediate causes of undernutrition. ${ }^{83}$

Second, there are divisions between those that work on humanitarian or emergency nutrition issues in shorter time scales versus those who work on longer-term nutrition development challenges. The rapid response needed in humanitarian work does not afford that community the time to reflect on broader ideologies with respect to working with the private sector (beyond standard institutional due diligence). Food assistance inherently needs private sector partnership to swiftly deliver food (and sometimes specialized foods in non-spoilage packaging) to hard-to-reach places through sophisticated logistical operations, and to prepare and provide supplementary food products, such as ready-touse therapeutic foods to treat acute severe undernutrition.

Third, another fault line exists in the nutrition community between those who work on undernutrition and those who work on overweight, obesity and diet-related NCD agendas. Much of the obesity community has been hesitant to engage with private sector due to the latter's production of energy dense, nutrient-poor, unhealthy food products that contribute to the burden of malnutrition and their design of food environments that tend to be coercive such as in the sales and advertising of junk food to children or inexpensive highly processed, unhealthy foods (also known as junk food that is high in added sugars, sodium and unhealthy fats). ${ }^{42,84-88}$

"There is the challenge of speaking a common language and having trust in one another, and that is related, again, to knowing people on the personal level. How do you build confidence in one another if you've never worked together?" (I18).

These differing world views and divergent interests create different relationships with the private sector, with varying degrees of trust and suspicion, and deep ideological fissures. These decisions are highly debated in the nutrition community, particularly in fora such as the Scaling Up Nutrition Movement and the United Nations Committee on World Food Security. Unresolved, these differences split practitioners into groups that use different programmatic models to address malnutrition. In addition, addressing these different forms of malnutrition presents unique opportunities, risks and histories of PPP arrangements. One example of success is the long-standing fortification programs in low- and middle-income countries which have engaged governments with the private sector in fortifying staple grains to improve micronutrient deficiencies. ${ }^{89-92}$ As a result, some public sector actors are more willing than others, or indeed consider it absolutely essential, to work with private sector. These decisions come down to individual researchers or organizations. This fragmentation is exacerbated by disagreements among nutrition actors on the advisability of working with the private sector, an issue discussed below. ${ }^{40}$

Power Imbalance in Nutrition That Favors the Private Sector The third challenge relates to power imbalances that favor the private sector. Public institutions and non-profit organizations are often too weak to provide a counterbalance to private sector influence, creating disincentives for partnering with the private sector in the form of PPPs (I10, I14, I15)..$^{93-97}$ Private sector actors are involved in almost all aspects of the production, processing, distribution, marketing and sale of food, dominating many of these functions. ${ }^{97}$ Moreover, some governments find regulating the nutrition and food space challenging due to the significant power of the private sector. ${ }^{98}$ One example where government has used regulation is through government-led taxes on certain food and beverage commodities deemed to be unhealthy, such as soda. Taxes have worked in some places, such as Mexico, ${ }^{98}$ however in other places, such as New York City's soda tax and Denmark's saturated fat tax, regulation failed to get off the ground, in part due to private sector lobbying and messaging to the public. ${ }^{99,100}$ Larger, more established private sector actors, particularly those which have undergone consolidation and have significant shares of key markets, use their power to override government voice to set agendas. ${ }^{43}$ Respondents speak to these power imbalances:

"Food and beverage industry has incredible power. Not only economically, but with political power. So can you have dinner with the devil? Well, you need to really have your tools to defend from what they are going to do to you. So, probably, there's a perception that we don't have those tools" (I14).

"Big Food corporations have used nutritional positioning to bolster their power and influence in the sector. Through lobbying 
and participation in nutritionally focused public-private partnerships, they have directly sought to influence policy and governance. Through market dominance in the nutritionally enhanced food sector, and participation in nutrition-focused rule-setting activities in agri-food supply chains, they have gained power to influence policy agendas." ${ }^{37}$

The public sector's lack of influence can also be tied to market forces. ${ }^{101}$ One respondent below noted that even if governments were to gain power in this domain and create meaningful food-based dietary guidelines and public procurement programs, ${ }^{14,102,103}$ fiscal instruments such as taxes on soda and unhealthy junk food, or regulations on advertising junk food to children, market forces and consumer demands are still important drivers of change. ${ }^{104}$ Respondents (I2, I5, I8, I9, I15) noted these market forces of consumer demand, saying:

"I think when we talk about PPPs in the context of nutrition, the first step is to acknowledge that, in fact, public players have very little influence on people's diets and their behaviors" (I10).

\section{Mistrust of the Private Sector}

The fourth challenge is that many public sector actors and researchers mistrust the private sector due to a long history of wrongdoings towards public health goals. ${ }^{85,105-107}$ One example is the consistent violation of the World Health Assembly adopted International Code of Marketing Breastmilk Substitutes (I6, 9, I12, I14, I16, I18). The Code is meant to protect exclusive breastfeeding of infants younger than six months, and to position it as a complement to other foods for older infants. It is intended to protect mothers, health workers and the health systems in which they work from commercial promotion of breastmilk substitutes that undermine breastfeeding. A Save the Children report found many examples of continued violations of the established Code by some manufacturers of breast-milk substitutes (I2, I6, I9, I12) ${ }^{108}$ If public sector organizations or individuals (both development practitioners or researchers) do get involved with Code violators, they are often shamed. Interviewees expressed that certain private sector organizations are perceived to be a "no go" for engaging with the public sector because of past behavior with breaking the Code:

"The public nutrition sector doesn't want to work with any of the multinationals that produce infant formula. So Danone, Nestle, and most of the dairy-related industries are not at the table or not accepted to work together" (I18).

Another transgression is the rampant availability and aggressive advertising of cheap junk food and sugar sweetened beverages to children (I12, I14, I16, I18)..$^{29,101,104,109}$ One study found that junk food advertising by the private sector is nearly 30 times what governments spend on healthy eating in the United Kingdom. ${ }^{110}$ In the United States, children ages 2 to 11 see an average of 10 food advertisements a day with most of those marketing unhealthy foods. ${ }^{111}$ Respondents note reservations about establishing PPPs given the behavior of the large, multi- and trans-national companies in the food environment space:

"[There is] nervousness about large food companies today.
[There is] clear evidence of the effect of poor diets on noncommunicable diseases and for a long time, the resistance of the food companies to acknowledge the role they are playing. To a large extent, they still try to work around that by placing the blame on individual behavior and lifestyles and choices rather than the environment that they are helping to create, not only the food environment, but the information and marketing environment around food" (I12).

"Companies will be working with you on the one hand but then lobbying against you on the other. Right? So these companies, especially the big ones... can be working with their sustainability team and the corporate social responsibility team on an initiative. And then you turn around and their government relations team in Washington DC is up on the Hill trying to kill that piece of legislation that would actually help solve the problem that you're trying to work on with your sustainability team" (I16).

The issue of whether to engage the private sector divides the nutrition community. ${ }^{82}$ Some argue that partnering with the private sector is impermissible because of the inherent conflicts of interest between corporations that profit from unhealthy food and public health collaborations. Others are willing to collaborate, finding it unrealistic to avoid the private sector because they are significant actors in food systems. Still others are open to communication but not to official partnership and instead engage at most in dialogue. Respondents expressed that these differences within the nutrition community affect the possibility of establishing PPPs:

"[We have] an inability to come together on a coherent set of demands...as a function of some people have stronger ideological opposition to the industry and PPPs than others" (I12).

"You'll always have vocal elements of the nutrition sector that come with a certain ideology...you'll always have a group of people that will see nutrition as a public good that should be delivered by public channels...lots of the rhetoric around the $[P P P]$ pushback relates to protecting populations from an evil private sector" (I10).

Factors Hampering the Success of Nutrition-Related PPPs These difficulties - nutrition's complex causal pathways, weak global governance of nutrition, private sector power and transgressions, and nutrition community mistrust of private sector actors - present obstacles not only to the establishment of PPPs but to their effectiveness once created. Nutritionrelated PPPs commonly face three problems that arise from effectiveness complexities: goal misalignment, power imbalances pertaining to resource contributions, and inadequate accountability mechanisms.

\section{Goal Ambiguity and Misalignment}

The public sector comes to the table with public health objectives and the private sector with profit-making objectives. These goals often clash, hampering PPP performance (I2, I4, I6, I7, I12, I14, I15, I18, I19). Speaking about PPP goal ambiguity or lack of clarity, informants remark:

"Depending on which nutrition scientists are in the room, 
in the case of the governance mechanisms, it's not even clear that you can get agreement among the nutritionists" (I12).

"I find myself wanting there to be a firm contract and set of agreements in hand that are measurable and enforceable. Only then could both sides proceed or especially only then would the nutrition community or members of it proceed. Absent that kind of formal agreement, I don't think that this mistrust issue can be overcome" (I12).

Informants note that conflicts of interest underpin goal misalignment problems, a difficulty particularly acute in the nutrition research community where industries have funded research that benefits their own products and bottom-line (I2, I6, I13, I14, I16). ${ }^{57}$ One respondent compared this conflict of interest to the health sector's relationship with pharmaceutical companies:

"In nutrition, it feels like we're still at a stage when everybody is kind of afraid of, especially from the public side, afraid of conflicts of interest rather than saying that's the way it is. And we're just going to be very pragmatic in how we approach that because food is coming almost entirely from the private sector and there is no way around it. Comparing the health sector to the nutrition sector, there is quite a gap in the way public sector interacts with businesses" (I3).

Others noted the dearth of individuals who might help transcend the mistrust between public and private sector actors. They note that the shared space between sectors and how to engage within it is unclear (I10, I18):

"There aren't that many people out there practiced at bridging these sectors. They usually come from their own sector, and they reach out into the other one, and they pretend they can talk the talk. But there's very few examples of people that actually understand and empathize with the motivations of the various sectors and can serve as a bridging agent" (I10).

\section{Resource Imbalances}

Resource problems also hamper PPP performance. ${ }^{78}$ The PPP mechanism is partly designed to address the issue of affordability by pooling resources from various sources to overcome the limited funding available in the public sector, which often brings in-kind contributions to the table. Governments do not invest enough in nutrition within their national budgets nor in official development assistance (ODA) with less than $1 \%$ of ODA going towards nutrition. ${ }^{112}$ However, with any partnership there is a tendency to value tangible financial resources above intangible resources such as capacities, expertise, reputation or networks. ${ }^{78}$ Hence partners committing more financial resources-almost always the private sector - tend to have greater bargaining power. This unequal power relationship within PPPs can create an environment in which weaker partners feel detached from the decision-making and management processes. ${ }^{78}$

Another resource problem is that a large number of informal or small-scale players in the private sector lack capacity to effectively engage in the partnership and deliver on the agreedupon goals. ${ }^{15,113}$ They do not have the technical know-how or human capacity to effectively engage in the partnership and deliver on the agreed-upon goals (I1, I9. I10, I14, I18). ${ }^{15,114,115}$
While SMEs are flexible and can quickly respond to consumer demands, their ability to address growing concerns of food safety, traceability and health and environmental sourcing constrains their ability to partner effectively. ${ }^{116-118}$ One interviewee expressed concern for SEMEs:

"SMEs-- I think they are willing but haven't necessarily the capacity or the know-how, how to work it" (I18).

Nevertheless, fortification and supplementation programs have multiple examples of where SMEs have successfully developed partnerships with the public sector. ${ }^{38}$

\section{Weak Accountability}

Nutrition-related PPPs also face problems with accountability and transparency (I4, I6, I8, I9, I12, I15)..$^{12,30,63,104,119,120}$ Accountability means:

1. Answerability: key actors provide an account of their decision and actions to relevant stakeholders using a trusted, transparent, responsive, credible and inclusive process that provides meaningful and verifiable information ${ }^{104}$; and

2. Enforceability: key actors comply with established standards and codes of conduct, and are subject to penalties or restrictions when they do not deliver on their pledges, commitments and obligations. ${ }^{119}$

A lack of civil society engagement hampers nutrition PPP accountability. ${ }^{121}$ However civil society organizations are key to holding governments and their partners to account. Vehicles such as the Civil Society Mechanism of the UN Committee on World Food Security could be more empowered to play a more significant role in ensuring that PPPs formed meet certain transparency and ethical metrics. As one respondent expressed:

"There is a lack of understanding about how we engage civil society who can add some accountability perspective, and sometimes evidence in terms of how not just which policies should be designed but downstream through implementation, the actual impacts of those policies, particularly to vulnerable groups" (I15).

Weak monitoring and evaluation mechanisms also make accountability difficult (I1, I5, I6, I12). Nutrition-related PPPs have rarely been subject to independent evaluation, a function in part of the fact that most are new. ${ }^{79}$ The earlier mentioned complexity of detecting causality also poses a problem for evaluation. As one respondent puts it:

"The resources required for a great evaluation or the resources required for proper monitoring and interpretation and enforcement could be a stumbling block, likely because the complexity of the problem is such that it would take enormous resources to untangle what's actually going on and where the accountability or blame lies if the articulated goals are not being achieved" (I12).

In nutrition, there are examples of effective accountability mechanisms. For instance, the Access to Nutrition Index ranks the world's largest food and beverage companies on their nutrition-related commitments, practices and performance globally. This can provide a starting point for public sector entities to assess these companies' suitability to partner based on their nutrition policies, product profiles and marketing 
strategies.

There are learnings from other sectors as well. The health sector provides insight for creating successful accountability mechanisms and partnership arrangements including the GAVI Vaccine Alliance and the non-profit organization PATH, which have established successful PPPs in public health. ${ }^{122}$ There are also many examples of where agriculture PPPs have worked effectively. ${ }^{123,124}$ For example, one PPP examined from the literature established that improved women's access to training, marketing, extension and financial services in producing local vegetables in India. ${ }^{125}$

\section{Discussion}

In the field of nutrition, discussion on the legitimacy and effectiveness of PPPs is polarized. Some argue that PPPs offer the potential to improve diet and nutrition outcomes by harnessing resources, reach, relationships and knowledge from both government and private sector actors. Others express deep mistrust of the private sector, viewing the food industry as prioritizing profit to the detriment of public health and as a cause of malnutrition, and therefore incapable of being part of the solution.

Of the seven factors that hinder success highlighted in this study, the issues of trust and power imbalances are the most challenging to overcome. Trust is particularly difficult to generate when many food and beverage industry players market products that harm public health and the environment. Lessons from other sectors reveal that effective partnerships depend on trust, transparent information sharing and effective management of conflicts of interest. ${ }^{33,124,126-129}$ Private sector actors also mistrust those in the public sector, shaping the former's interest in partnership. ${ }^{119}$

With power imbalances, more established private-sector actors, particularly those that have undergone consolidation and have significant shares of key markets, have been known to use their power to override government voice and agency to set agendas. ${ }^{43,93-97}$ Unequal power relationship within PPPs can create an environment in which weaker partners (including local public and even SMEs, civil society organizations, and community organizations) feel detached from the decisionmaking and management processes of partnerships. ${ }^{78}$ This detachment can lead to reduced ownership and agency of these actors, which can threaten dialogue on accountability and transparency. Some governments find regulating the nutrition and food space challenging due to a lack of capacity to govern, or the "will to govern" the multiple actors involved, amongst which the private sector tends to dominate. ${ }^{127}$

There are few third-party evaluations of PPPs, and those reports that exist provide limited guidance on how to construct PPPs that serve nutrition outcomes. Much of the literature focuses on the power of big business in the food sector, particularly with regard to their ability to influence public sector nutrition research specifically. There is much less published on how PPPs operate in practice for diet and nutrition outcomes-how these partnerships are formulated and structured, and how conflicts of interest are prevented, minimized and managed.

The dearth of consideration of independent third-party evaluations of PPPs-because few exist-is a limitation of this study. Another limitation is that some experts who had strong aversion towards PPPs did not want to be interviewed because their view was that PPPs should not exist, and therefore, an evaluation was pointless. These limitations notwithstanding, this study was comprehensive in drawing on interviews with a wide range of experts from both public and private sectors, and an extensive literature in nutrition related to private sector engagement and controversies in nutrition research.

\section{Conclusion}

With the renewed attention on food systems, in particular the UN Food Systems Summit in 2021, there is an interest in how to effectively engage the private sector in food systems that would result in positive outcomes for public health nutrition, environmental sustainability and equity. The call for PPPs will be on the table at the Summit for consideration in which accountability mechanisms and declarations of interest will need to be clearly stated and established.

If PPPs are considered as a mechanism to address malnutrition and diets, the terms of partnership or more broadly, engagement, should be led by government, and the private sector should be steered to understand government priorities to promote healthy diets and nutrition. Many PPPs are currently impeded by constraints such as: lack of the prerequisite technical skills, limited resources, power imbalances, and lack of trust. In order to address trust deficits, it would be necessary for outside brokers to bring public and private sectors actors together. Trust issues cannot be resolved without direct involvement of the actors affected. Transparency and accountability are crucial for PPPs to work effectively and those accountability structures should track progress and sanction poor progress or inappropriate behavior made by partners. ${ }^{128}$ Additionally, there is a need to strengthen the evidence base in order to share and build upon lessons from the successes, as well as the challenges, of creating sustainable PPPs.

It is important to consider whether a partnership is necessary for tackling a specific public health nutrition objective. Hawkes and Buse ${ }^{130}$ suggest that before engaging with private sector, three questions should be answered: 1. Would engaging with private sector help achieve the objective faster and more effectively?

2. Would the interests involved (on both sides) enhance or threaten the likelihood of achieving the specific objective as well as longer-term public health objectives?

3. If interaction is a viable option, what form of engagement would most effectively achieve the objective while accounting for the different interests: a real partnership or less formal type of collaboration?

The issues that are most amenable to partnerships are those with clear causal pathways to improved nutrition, and ones where private sector interests are aligned with rather than in opposition to improved public health.

Strengthened accountability systems would support government leadership and stewardship, incentivize private sector actors to include nutrition among its goals, and reinforce the engagement of civil society in creating demand for healthy 
food environments and monitoring progress towards the nutrition agenda objectives. But processes of engagement need to be transparent, open and inclusive. Engagement should not compromise any individual organization's independence or reputation, and mutual accountability towards public nutrition goals should be the main goal. Governments must be the enactors, through mandatory regulation, to manage conflicts of interest. Voluntary or self-regulation of the private sector by the private sector is a less viable option to institute meaningful change and trust.

Governments need to exert power and shepherd their food systems in the directions that promote public health. They must create meaningful food-based dietary guidelines and public procurement programs, ${ }^{104}$ as well as fiscal instruments such as taxes on soda and unhealthy junk food, and regulate advertising junk food to children ${ }^{103}$ to keep the private sector in check. Only when these factors are in place and better public health nutrition outcomes are assured through them can PPPs be considered.

\section{Acknowledgements}

The authors would like to thank those who took the time to interview and review earlier versions of the manuscript. We are not including their names for anonymity sake.

\section{Ethical issues}

The study protocol was cleared through the Institutional Review Board of the Johns Hopkins University, which granted the study exempt status because it focused on public policy and was deemed to pose minimal risk to informants.

\section{Competing interests}

Authors declare that they have no competing interests.

\section{Authors' contributions}

$J F$, YRS and JS contributed to the design and overall conception of the research. YRS, JF, TS and SD performed the implementation of the literature research and conducted interviews. YRS, TS and SD analyzed the data and performed the formal analysis. JF, YRS, JS and TS contributed to the writing and the final version of the manuscript.

\section{Funding}

Funding was received from the Global Alliance for Improved Nutrition to carry out this work.

\section{Authors' affiliations}

'The Nitze School of Advanced International Studies, Johns Hopkins University, Baltimore, MD, USA. ${ }^{2}$ The Bloomberg School of Public Health, Johns Hopkins University, Baltimore, MD, USA. ${ }^{3}$ The Berman Institute of Bioethics, Johns Hopkins University, Baltimore, MD, USA. ${ }^{4}$ Independent Consultant, Singapore, Singapore. ${ }^{5}$ Independent Consultant, New Delhi, India.

\section{References}

1. Swinburn BA, Kraak VI, Allender S, et al. The global syndemic of obesity, undernutrition, and climate change: the Lancet Commission report. Lancet. 2019;393(10173):791-846. doi:10.1016/s0140-6736(18)32822-8

2. Fanzo J, Hawkes C, Udomkesmalee E, et al. 2018 Global Nutrition Report: Shining a Light to Spur Action on Nutrition. Bristol, UK: Development Initiatives; 2018.

3. Temple NJ. A comparison of strategies to improve population diets: government policy versus education and advice. J Nutr Metab. 2020; 2020:5932516. doi:10.1155/2020/5932516

4. Haddad L, Hawkes C, Waage J, et al. Food Systems and Diets: Facing the Challenges of the 21st Century. Global Panel on Agriculture and Food Systems for Nutrition; 2016.

5. Masters WA, Rosettie K, Kranz S, et al. Priority interventions to improve maternal and child diets in Sub-Saharan Africa and South Asia. Matern
Child Nutr. 2018;14(2):e12526. doi:10.1111/mcn.12526

6. Mozaffarian D. Diets from around the world--quality not quantity. Lancet. 2011;378(9793):759. doi:10.1016/s0140-6736(11)61362-7

7. Mozaffarian D. Dietary and policy priorities to reduce the global crises of obesity and diabetes. Nat Food. 2020;1(1):38-50. doi:10.1038/s43016019-0013-1

8. Popkin BM, Adair LS, Ng SW. Global nutrition transition and the pandemic of obesity in developing countries. Nutr Rev. 2012;70(1):3-21. doi:10.1111/ j.1753-4887.2011.00456.x

9. Health effects of dietary risks in 195 countries, 1990-2017: a systematic analysis for the Global Burden of Disease Study 2017. Lancet. 2019; 393(10184):1958-1972. doi:10.1016/s0140-6736(19)30041-8

10. Kraak VI, Rincón-Gallardo Patiño S, Sacks G. An accountability evaluation for the International Food \& Beverage Alliance's Global Policy on Marketing Communications to Children to reduce obesity: a narrative review to inform policy. Obes Rev. 2019;20 Suppl 2:90-106. doi:10.1111/ obr. 12859

11. Fracassi P, Siekmans K, Baker P. Galvanizing political commitment in the UN Decade of Action for Nutrition: assessing commitment in membercountries of the Scaling Up Nutrition (SUN) Movement. Food Policy. 2020;90:101788. doi:10.1016/j.foodpol.2019.101788

12. Kraak VI, Swinburn B, Lawrence M, Harrison P. An accountability framework to promote healthy food environments. Public Health Nutr. 2014;17(11):2467-2483. doi:10.1017/s1368980014000093

13. Zhou M, Rincón-Gallardo Patiño S, Hedrick VE, Kraak VI. An accountability evaluation for the responsible use of celebrity endorsement by the food and beverage industry to promote healthy food environments for young Americans: a narrative review to inform obesity prevention policy. Obes Rev. 2020;21(12):e13094. doi:10.1111/obr.13094

14. Mozaffarian D, Angell SY, Lang T, Rivera JA. Role of government policy in nutrition-barriers to and opportunities for healthier eating. BMJ. 2018;361:k2426. doi:10.1136/bmj.k2426

15. Glopan. Improving Diets in an Era of Food Market Transformation: Challenges and Opportunities for Engagement Between the Public and Private Sectors. Policy Brief No. 11. London, UK: Global Panel on Agriculture and Food Systems for Nutrition; 2018.

16. Roehrich JK, Lewis MA, George G. Are public-private partnerships a healthy option? a systematic literature review. Soc Sci Med. 2014;113:110119. doi:10.1016/j.socscimed.2014.03.037

17. Levine R, Kuczynski D. Global Nutrition Institutions: Is There an Appetite for Change? Center for Global Development; 2009.

18. Dukeshire S. Concentration, consolidation, and control: how big business dominates the food system. J Agric Food Syst Community Dev. 2013; 4(1):171-173. doi:10.5304/jafscd.2013.041.010

19. Clapp J, Isakson SR. Risky returns: the implications of financialization in the food system. Dev Change. 2018;49(2):437-460. doi:10.1111/ dech.12376

20. Howard PH, Goodman D, Goodman MK. Concentration and Power in the Food System: Who Controls What We Eat? New York: Bloomsbury Academic; 2016.

21. Fanzo J, McLaren R. An overview of the ethics of eating and drinking. In: Meiselman $\mathrm{HL}$, ed. Handbook of Eating and Drinking. Cham: Springer; 2020:1095-1115. doi:10.1007/978-3-030-14504-0_82

22. Bennett J, Boles O, Crossley R. A Recipe for Success: How Food Companies Can Profit from Consumer Health. London: IBLF; 2007.

23. Lang T, Rayner G, Kaelin E. The Food Industry, Diet Physical Activity and Health: A Review of Reported Commitments and Practice of 25 of the World's Largest Food Companies. London: City University; 2006.

24. Wansink B, Huckabee M. De-marketing obesity. Calif Manage Rev. 2005; 47(4):6-18. doi:10.2307/41166314

25. Hamann R, Giamporcaro S, Johnston D, Yachkaschi S. The role of business and cross-sector collaboration in addressing the 'wicked problem' of food insecurity. Dev South Afr. 2011;28(4):579-594. doi:10.10 80/0376835x.2011.605581

26. Yach D. Food companies and nutrition for better health. Public Health Nutr. 2008;11(2):109-111. doi:10.1017/s1368980007001619

27. Yach $D$. The role of business in addressing the long-term implications of the current food crisis. Global Health. 2008;4:12. doi:10.1186/1744-86034-12

28. Yach D, Khan M, Bradley D, Hargrove R, Kehoe S, Mensah G. The role and challenges of the food industry in addressing chronic disease. Global Health. 2010;6:10. doi:10.1186/1744-8603-6-10 
29. Sacks G, Swinburn B, Kraak V, et al. A proposed approach to monitor private-sector policies and practices related to food environments, obesity and non-communicable disease prevention. Obes Rev. 2013;14 Suppl 1:38-48. doi:10.1111/obr.12074

30. Drewnowski A, Caballero B, Das JK, et al. Novel public-private partnerships to address the double burden of malnutrition. Nutr Rev. 2018;76(11):805-821. doi:10.1093/nutrit/nuy035

31. Austin JE. Strategic collaboration between nonprofits and businesses. Nonprofit Volunt Sect Q. 2000;29(1 suppl):69-97. doi:10.1177/0899764000291s004

32. Kraak VI, Story M. A public health perspective on healthy lifestyles and public-private partnerships for global childhood obesity prevention. J Am Diet Assoc. 2010;110(2):192-200. doi:10.1016/j.jada.2009.10.036

33. Kraak VI, Harrigan PB, Lawrence M, Harrison PJ, Jackson MA, Swinburn B. Balancing the benefits and risks of public-private partnerships to address the global double burden of malnutrition. Public Health Nutr. 2012;15(3):503-517. doi:10.1017/s1368980011002060

34. Hoddinott J, Gillespie S, Yosef S. Public-private partnerships and undernutrition: examples and future prospects. World Rev Nutr Diet. 2016;115:233-238. doi:10.1159/000442110

35. Rowe S, Alexander N, Kretser A, et al. Principles for building publicprivate partnerships to benefit food safety, nutrition, and health research. Nutr Rev. 2013;71(10):682-691. doi:10.1111/nure.12072

36. Organisation for Economic Co-operation and Development (OECD). International Migration Outlook 2016. Paris: OECD Publishing; 2016.

37. World Health Organization (WHO). Public-Private Partnerships (PPPs). WHO; 2010

38. Hoddinott JF, Gillespie S, Yosef S. Public-Private Partnerships and the Reduction of Undernutrition in Developing Countries. International Food Policy Research Institute; 2015.

39. Bryce J, Coitinho D, Darnton-Hill I, Pelletier D, Pinstrup-Andersen P. Maternal and child undernutrition: effective action at national level. Lancet. 2008;371(9611):510-526. doi:10.1016/s0140-6736(07)61694-8

40. Gillespie S, Haddad L, Mannar V, Menon P, Nisbett N. The politics of reducing malnutrition: building commitment and accelerating progress. Lancet. 2013;382(9891):552-569. doi:10.1016/s0140-6736(13)60842-9

41. Clapp J, Scrinis G. Big food, nutritionism, and corporate power. Globalizations. 2017;14(4):578-595. doi:10.1080/14747731.2016.12398 06

42. Johnston LM, Finegood DT. Cross-sector partnerships and public health: challenges and opportunities for addressing obesity and noncommunicable diseases through engagement with the private sector. Annu Rev Public Health. 2015;36:255-271. doi:10.1146/annurevpublhealth-031914-122802

43. Scrinis G. Reformulation, fortification and functionalization: Big Food corporations' nutritional engineering and marketing strategies. J Peasant Stud. 2016;43(1):17-37. doi:10.1080/03066150.2015.1101455

44. Nestle M. Food Politics: How the Food Industry Influences Nutrition and Health. Berkeley, CA: University of California Press; 2013.

45. Mialon M, Gomes FDS. Public health and the ultra-processed food and drink products industry: corporate political activity of major transnationals in Latin America and the Caribbean. Public Health Nutr. 2019;22(10):18981908. doi:10.1017/s1368980019000417

46. Mialon M, Mialon J. Analysis of corporate political activity strategies of the food industry: evidence from France. Public Health Nutr. 2018; 21(18):3407-3421. doi:10.1017/s1368980018001763

47. Bowen GA. Naturalistic inquiry and the saturation concept: a research note. Qual Res. 2008;8(1):137-152. doi:10.1177/1468794107085301

48. Shiffman J, Quissell K, Schmitz HP, et al. A framework on the emergence and effectiveness of global health networks. Health Policy Plan. 2016;31 Suppl 1:i3-16. doi:10.1093/heapol/czu046

49. Wang $\mathrm{H}$, Xiong $\mathrm{W}, \mathrm{Wu}$ G, Zhu D. Public-private partnership in public administration discipline: a literature review. Public Manag Rev. 2018; 20(2):293-316. doi:10.1080/14719037.2017.1313445

50. Danaei G, Andrews KG, Sudfeld CR, et al. Risk factors for childhood stunting in 137 developing countries: a comparative risk assessment analysis at global, regional, and country levels. PLoS Med. 2016;13(11):e1002164. doi:10.1371/journal.pmed.1002164

51. Acosta AM, Fanzo J. Fighting Maternal and Child Malnutrition: Analysing the Political and Institutional Determinants of Delivering a National Multisectoral Response in Six Countries. Brighton, UK: Institute for Development Studies; 2012.
52. Reinhardt K, Fanzo J. Addressing chronic malnutrition through multi-sectoral, sustainable approaches: a review of the causes and consequences. Front Nutr. 2014;1:13. doi:10.3389/fnut.2014.00013

53. Black RE, Laxminarayan R, Temmerman M, Walker N. Disease Control Priorities, Third Edition (Volume 2): Reproductive, Maternal, Newborn, and Child Health. Washington, DC: World Bank Publications; 2016

54. Piwoz E, Sundberg S, Rooke J. Promoting healthy growth: what are the priorities for research and action? Adv Nutr. 2012;3(2):234-241. doi:10.3945/an.111.001164

55. Ruel MT, Alderman $\mathrm{H}$. Nutrition-sensitive interventions and programmes: how can they help to accelerate progress in improving maternal and child nutrition? Lancet. 2013;382(9891):536-551. doi:10.1016/s01406736(13)60843-0

56. Institute of Medicine, Food and Nutrition Board \& Committee on an Evidence Framework for Obesity Prevention Decision Making. Bridging the Evidence Gap in Obesity Prevention: A Framework to Inform Decision Making. National Academies Press; 2010.

57. Pérez-Escamilla R, Lutter CK, Rabadan-Diehl C, et al. Prevention of childhood obesity and food policies in Latin America: from research to practice. Obes Rev. 2017;18 Suppl 2:28-38. doi:10.1111/obr.12574

58. Reilly JJ, Martin A, Hughes AR. Early-life obesity prevention: critique of intervention trials during the first one thousand days. Curr Obes Rep. 2017;6(2):127-133. doi:10.1007/s13679-017-0255-x

59. Sacks G, Kwon J, Ananthapavan J. The application of an evidence framework for obesity prevention at the population-level. Curr Obes Rep. 2020;9(2):150-158. doi:10.1007/s13679-020-00376-z

60. Richardson AS, Chen C, Sturm R, et al. Obesity prevention interventions and implications for energy balance in the United States and Mexico: a systematic review of the evidence and meta-analysis. Obesity (Silver Spring). 2019;27(9):1390-1403. doi:10.1002/oby.22540

61. Nugent R, Levin C, Grafton D, Fanzo J, Remans R, Anderson CL. Indicators for nutrition-friendly and sustainable food systems. In: Global Nutrition Report 2015: Actions and Accountability to Advance Nutrition and Sustainable Development. International Food Policy Research Institute (IFPRI); 2015

62. Haddad LJ, Achadi E, Bendech MA, et al. Global Nutrition Repor 2014: Actions and Accountability to Accelerate the World's Progress on Nutrition. Washington, DC: International Food Policy Research Institute (IFPRI); 2015. doi:10.2499/9780896295643

63. International Food Policy Research Institute. Global Nutrition Report 2015: Actions and Accountability to Advance Nutrition and Sustainable Development. International Food Policy Research Institute (IFPRI); 2015.

64. Hurlimann T, Peña-Rosas JP, Saxena A, Zamora G, Godard B. Ethical issues in the development and implementation of nutrition-related public health policies and interventions: A scoping review. PLoS One. 2017; 12(10):e0186897. doi:10.1371/journal.pone.0186897

65. Jerling J, Pelletier D, Fanzo J, Covic N. Supporting multisectoral action: capacity and nutrition leadership challenges facing Africa. In: Covic N, Hendriks SL, eds. Achieving a Nutrition Revolution for Africa: The Road to Healthier Diets and Optimal Nutrition. Washington, DC: International Food Policy Research Institute (IFPRI); 2016:147-169.

66. 66. White M, Barquera S, Buenrostro N. The double burden of malnutrition: a Latin American perspective. Sight and Life. 2018;32(2):2428

67. Reich MR, Balarajan Y. Political Economy Analysis for Food and Nutrition Security. Washington, DC: World Bank; 2012.

68. Balarajan Y, Reich MR. Political economy challenges in nutrition. Global Health. 2016;12(1):70. doi:10.1186/s12992-016-0204-6

69. Darnton-Hill I, Samman S. Challenges and opportunities in scaling-up nutrition in healthcare. Healthcare (Basel). 2015;3(1):3-19. doi:10.3390/ healthcare 3010003

70. Garrett JL, Natalicchio M. Working Multisectorally in Nutrition: Principles, Practices, and Case Studies. International Food Policy Research Institute (IFPRI); 2010.

71. Palmer AC, West KP. A quarter of a century of progress to prevent vitamin A deficiency through supplementation. Food Rev Int. 2010;26(3):270-301. doi:10.1080/87559129.2010.484116

72. Clark LF. Are innovative ready to use therapeutic foods more effective, accessible and cost-efficient than conventional formulations? a review. Outlook Agric. 2020;49(4):267-277. doi:10.1177/0030727020932184

73. Kumar D, Raghav P, Bhardwaj P, Kumar N. Harnessing the potential of private sector in nutrition: a prerequisite for meeting goal 2 of Sustainable 
Development Goals (SDG) 2030. Indian J Community Fam Med. 2017;3(2):4. doi:10.4103/2395-2113.251890

74. Rowe S, Alexander N. Public-private partnerships in nutrition: meeting the public-private communication challenge. Nutr Today. 2014;49(2):83-86. doi:10.1097/nt.0000000000000023

75. Gillespie S, Poole N, van den Bold M, Bhavani RV, Dangour AD, Shetty P. Leveraging agriculture for nutrition in South Asia: what do we know, and what have we learned? Food Policy. 2019;82:3-12. doi:10.1016/j. foodpol.2018.10.012

76. Hermans F, Geerling-Eiff F, Potters J, Klerkx L. Public-private partnerships as systemic agricultural innovation policy instruments-Assessing their contribution to innovation system function dynamics. NJAS Wageningen J Life Sci. 2019;88:76-95. doi:10.1016/j.njas.2018.10.001

77. Knai C, Petticrew M, Durand MA, et al. Has a public-private partnership resulted in action on healthier diets in England? an analysis of the Public Health Responsibility Deal food pledges. Food Policy. 2015;54:1-10. doi:10.1016/j.foodpol.2015.04.002

78. Rampa F, Karaki K. Ending Hunger and Malnutrition: The Role of PublicPrivate Partnerships. Rome: Save the Children Italy; 2017.

79. van Liere MJ, Tarlton D, Menon R, Yellamanda M, Reerink I. Harnessing private sector expertise to improve complementary feeding within a regulatory framework: where is the evidence? Matern Child Nutr. 2017;13 Suppl 2:e12429. doi:10.1111/mcn.12429

80. Pelletier D, Gervais S, Hafeez-Ur-Rehman H, Sanou D, Tumwine J. Boundary-spanning actors in complex adaptive governance systems: the case of multisectoral nutrition. Int J Health Plann Manage. 2018; 33(1):e293-e319. doi:10.1002/hpm.2468

81. Lamstein S, Pomeroy-Stevens A, Webb P, Kennedy E. Optimizing the multisectoral nutrition policy cycle: a systems perspective. Food Nutr Bull. 2016;37(4 Suppl):S107-S114. doi:10.1177/0379572116675994

82. De Costa A, Johansson E, Diwan VK. Barriers of mistrust: public and private health sectors' perceptions of each other in Madhya Pradesh, India. Qual Health Res. 2008;18(6):756-766. doi:10.1177/1049732308318504

83. Menon P, Stoltzfus RJ. Building convergence in science, programs, and policy actions on child undernutrition: symposium rationale and overview. Adv Nutr. 2012;3(2):224-226. doi:10.3945/an.111.001115

84. Lake AA. Neighbourhood food environments: food choice, foodscapes and planning for health. Proc Nutr Soc. 2018;77(3):239-246. doi:10.1017/ s0029665118000022

85. Brownell KD, Warner KE. The perils of ignoring history: Big Tobacco played dirty and millions died. How similar is Big Food? Milbank Q. 2009; 87(1):259-294. doi:10.1111/j.1468-0009.2009.00555.x

86. Kovic Y, Noel JK, Ungemack JA, Burleson JA. The impact of junk food marketing regulations on food sales: an ecological study. Obes Rev. 2018;19(6):761-769. doi:10.1111/obr.12678

87. Taillie LS, Busey E, Stoltze FM, Dillman Carpentier FR. Governmental policies to reduce unhealthy food marketing to children. Nutr Rev. 2019; 77(11):787-816. doi:10.1093/nutrit/nuz021

88. Huang TT, Yaroch AL. A public-private partnership model for obesity prevention. Prev Chronic Dis. 2009;6(3):A110.

89. Salam RA, Das JK, Ahmed W, Irfan O, Sheikh SS, Bhutta ZA. Effects of preventive nutrition interventions among adolescents on health and nutritional status in low-and middle-income countries: a systematic review and meta-analysis. Nutrients. 2019;12(1). doi:10.3390/nu12010049

90. Tsang BL, Moreno R, Dabestani N, Pachón H, Spohrer R, Milani P. Public and private sector dynamics in scaling up rice fortification: the Colombian experience and its lessons. Food Nutr Bull. 2016;37(3):317328. doi:10.1177/0379572116646897

91. Mehansho $\mathrm{H}$. Eradication of iron deficiency anemia through food fortification: the role of the private sector. J Nutr. 2002;132(4 Suppl):831S833S. doi:10.1093/jn/132.4.831S

92. Garrett GS, Manus C, Bleuthner A. Chapter 11 - The importance of public-private collaboration in food fortification programs. In: Mannar MGV, Hurrell RF, eds. Food Fortification in a Globalized World. Academic Press; 2018:113-120. doi:10.1016/b978-0-12-802861-2.00011-0

93. Fuchs $D$, Kalfagianni A, Arentsen M. Retail power, private standards, and sustainability in the global food system. In: Corporate Power in Global Agrifood Governance. MIT Press; 2009:29-59.

94. Sodano V. A power-based approach to the analysis of the food system. In: Bijman J, Omta SWF, Trienekens JH, Wijnands JHM, Wubben EFM, eds. International Agri-Food Chains and Networks. Wageningen Academic Publishers; 2006:199-215.
95. Stevenson MA. The relevance of the public-private partnership paradigm to the prevention of diet-associated non-communicable diseases in wealthy countries. Glob Public Health. 2015;10(8):930-946. doi:10.1080 /17441692.2015.1012528

96. Pelto GH, Backstrand JR. Interrelationships between power-related and belief-related factors determine nutrition in populations. J Nutr. 2003; 133(1):297S-300S. doi:10.1093/jn/133.1.297S

97. Chen S. Multinational corporate power, influence and responsibility in global supply chains. J Bus Ethics. 2018;148(2):365-374. doi:10.1007/ s10551-016-3033-x

98. Colchero MA, Rivera-Dommarco J, Popkin BM, Ng SW. In Mexico, evidence of sustained consumer response two years after implementing a sugar-sweetened beverage tax. Health Aff (Millwood). 2017;36(3):564571. doi:10.1377/hlthaff.2016.1231

99. Lerner IM. Can New York swallow a soda tax? N Y State Dent J 2010;76(2):10-11.

100. Smed S, Scarborough P, Rayner M, Jensen JD. The effects of the Danish saturated fat tax on food and nutrient intake and modelled health outcomes: an econometric and comparative risk assessment evaluation. Eur J Clin Nutr. 2016;70(6):681-686. doi:10.1038/ejcn.2016.6

101. Baker P, Friel S. Food systems transformations, ultra-processed food markets and the nutrition transition in Asia. Global Health. 2016;12(1):80. doi:10.1186/s12992-016-0223-3

102. Herforth A, Arimond M, Álvarez-Sánchez C, Coates J, Christianson K, Muehlhoff $\mathrm{E}$. A global review of food-based dietary guidelines. Adv Nutr. 2019;10(4):590-605. doi:10.1093/advances/nmy130

103. Herforth A, Ahmed S. The food environment, its effects on dietary consumption, and potential for measurement within agriculture-nutrition interventions. Food Security. 2015;7(3):505-520. doi:10.1007/s12571015-0455-8

104. Swinburn B, Kraak V, Rutter $\mathrm{H}$, et al. Strengthening of accountability systems to create healthy food environments and reduce global obesity. Lancet. 2015;385(9986):2534-2545. doi:10.1016/s0140-6736(14)61747-5

105. Brownell KD. Thinking forward: the quicksand of appeasing the food industry. PLoS Med. 2012;9(7):e1001254. doi:10.1371/journal. pmed. 1001254

106. Freedhoff $Y$, Hébert PC. Partnerships between health organizations and the food industry risk derailing public health nutrition. CMAJ. 2011; 183(3):291-292. doi:10.1503/cmaj.110085

107. Haddad L. Reward food companies for improving nutrition. Nature. 2018; 556(7699):19-22. doi:10.1038/d41586-018-03918-7

108. Mason F, Greer H. Don't Push It: Why the Formula Milk Industry Must Clean Up Its Act. Save the Children; 2013.

109. Ludwig DS, Nestle M. Can the food industry play a constructive role in the obesity epidemic? JAMA. 2008;300(15):1808-1811. doi:10.1001/ jama.300.15.1808

110. O'Dowd A. Spending on junk food advertising is nearly 30 times what government spends on promoting healthy eating. BMJ. 2017;359:j4677. doi:10.1136/bmj.j4677

111. Abbasi J. Junk food ads reach children despite food industry selfregulation. JAMA. 2017;317(23):2359-2361. doi:10.1001/jama.2017.4653

112. 2020 Global Nutrition Report - Global Nutrition Report. Global Nutrition Report. https://globalnutritionreport.org/reports/2020-global-nutritionreport/. Published 2020.

113. De Schutter $\mathrm{O}$. The political economy approach to food systems reform. In: Harris J, Anderson M, Clément C, Nisbett N, eds. The Political Economy of Food. Brighton: IDS; 2019.

114. Nwuneli N, Robinson E, Humphrey J, Henson S. The Role of Businesses in Providing Nutrient-Rich Foods for the Poor: Two Case Studies in Nigeria, IDS Evidence Report 64. Brighton: IDS; 2014.

115. Temu A, Waized B, Ndyetabula D, Robinson E, Humphrey J, Henson S. Mapping Value Chains for Nutrient-Dense Foods in Tanzania, IDS Evidence Report 76. Brighton: IDS; 2014.

116. Baregheh A, Rowley J, Sambrook S, Davies D. Food sector SMEs and innovation types. Br Food J. 2012;114(11):1640-1653. doi:10.1108/00070701211273126

117. Reardon T, Echeverria R, Berdegué J, et al. Rapid transformation of food systems in developing regions: highlighting the role of agricultural research \& innovations. Agric Syst. 2019;172:47-59. doi:10.1016/j. agsy.2018.01.022

118. Ortega DL, Tschirley DL. Demand for food safety in emerging and developing countries: a research agenda for Asia and sub-Saharan 
Africa. J Agribus Dev Emerg Econ. 2017;7(1):21-34. doi:10.1108/ jadee-12-2014-0045

119. Eggersdorfer M, Bird JK. How to achieve transparency in public-private partnerships engaged in hunger and malnutrition reduction. World Rev Nutr Diet. 2016;115:224-232. doi:10.1159/000442109

120. DiMartino $C$, Scott J. Private sector contracting and democratic accountability. Educ Policy.2013;27(2):307-333. doi:10.1177/0895904812465117

121. HLPE. Nutrition and Food Systems: A report by the High Level Panel of Experts on Food Security and Nutrition of the Committee on World Food Security. http://www.fao.org/fileadmin/user_upload/hlpe/hlpe_documents/ HLPE_Reports/HLPE-Report-12_EN.pdf. Published 2017.

122. Stevenson M. PATH: pioneering innovation for global health at the publicprivate interface. Third World Q. 2017;38(8):1873-1893. doi:10.1080/014 36597.2016.1233491

123. Ponnusamy K, Das MD, Bonny BP, Mishra S. PPP and gender mainstreaming in agriculture: lessons from field studies. Agric Econ Res Rev. 2014;27:147-155. doi:10.5958/0974-0279.2014.00017.2

124. Ferroni M, Castle P. Public-private partnerships and sustainable agricultural development. Sustainability. 2011;3(7):1064-1073. doi:10.3390/su3071064
125. Thorpe J. Procedural justice in value chains through publicprivate partnerships. World Dev. 2018;103:162-175. doi:10.1016/j. worlddev.2017.10.004

126. Ruckert A, Labonté R. Public-private partnerships (PPPs) in global health: the good, the bad and the ugly. Third World Q. 2014;35(9):15981614. doi:10.1080/01436597.2014.970870

127. Ponnusamy K. Impact of public private partnership in agriculture: a review. Indian J Agric Sci. 2013;83(8):803-808.

128. Spielman DJ, Hartwich F, Grebmer K. Public-private partnerships and developing-country agriculture: evidence from the international agricultural research system. Public Adm Dev. 2010;30(4):261-276. doi:10.1002/pad.574

129. Lawther WC, Martin LL. Private Financing of Public Transportation Infrastructure: Utilizing Public-Private Partnerships. Lexington Books; 2015.

130. Hawkes C, Buse K. Public health sector and food industry interaction: it's time to clarify the term 'partnership' and be honest about underlying interests. Eur J Public Health. 2011;21(4):400-401. doi:10.1093/eurpub/ ckr077 